\title{
Robust PLS models for soluble solids content and firmness determination in low chilling peach using near-infrared spectroscopy
}

\section{(NIR)}

\author{
Paloma Andrade Martins Nascimento ${ }^{\mathrm{a}}$, Lívia Cirino de Carvalho ${ }^{\mathrm{a}}$, \\ Luis Carlos Cunha Júnior ${ }^{\mathrm{b}}$, Fabíola Manhas Verbi Pereira ${ }^{\mathrm{c}}$, \\ Gustavo Henrique de Almeida Teixeira ${ }^{\mathrm{d}, *}$ \\ a Universidade Estadual Paulista (UNESP), Faculdade de Ciências Farmacêuticas (FCFAR), Campus de Araraquara. Rod. Araraquara- Jaú, km.1 s/n, Araraquara, \\ SP, Brazil \\ b Universidade Federal de Goiás (UFG), Escola de Agronomia (EA), Setor de Horticultura, Avenida Esperança s/n - Campus Universitário, 74.690-000, Goiânia, \\ GO, Brazil \\ ${ }^{\mathrm{C}}$ Universidade Estadual Paulista (UNESP), Instituto de Química (IQ), Campus de Araraquara, Rua Prof. Francisco Degni, 55, Araraquara, SP, Brazil \\ ${ }^{\mathrm{d}}$ Universidade Estadual Paulista (UNESP), Faculdade de Ciências Agrárias e Veterinárias (FCAV), Via de acesso Prof. Paulo Donato Castellane s/n, Jaboticabal, \\ SP, CEP 14.870-900, Brazil
}

A R T I C L E I N F O

Article history:

Received 3 June 2015

Received in revised form 6 August 2015

Accepted 11 August 2015

Available online 4 October 2015

\section{Keywords:}

Prunus persica L

Aurora 1

Maturity stages

Chemometrics

PLS

\begin{abstract}
A B S T R A C T
The objectives of this study was to develop partial least square (PLS) models using NIR spectroscopy for the determination of SSC and firmness in intact low chilling 'Aurora-1' peach fruit, and verify the influence of maturity stage and harvest season on the models to be developed (robustness). FT-NIR spectra were obtained as $\log 1 / \mathrm{R}$ with fruit harvested in 2013 at 3 maturity stages and in 2014 . The spectra were collected on the background and blush colour skin areas of the each fruit. Model performance was evaluated based on the values of root mean square error for prediction (RMSE $)$ and coefficient of determination $\left(\mathrm{R}_{\mathrm{P}}{ }^{2}\right.$ ) obtained from validation fruit set (Kennard-Stone), and prediction fruit set (2014). PCA could not group the fruit based on blush and background skin colour, maturity stages, and harvest season. The model constructed using the external validation method obtained a RMSE $\mathrm{VE}_{\mathrm{E}}$ of $1.08 \%$ with 11 latent variables $\left(\mathrm{LV}_{\mathrm{S}}\right)$ and $\mathrm{R}_{\mathrm{VE}}{ }^{2}$ of 0.59 . The prediction set, independent data, resulting in a less accurate model (RMSE $E_{P} 1.04 \%, R_{p}^{2} 0.45$ and $11 L_{S}$ ). The same trend happened for determining firmness with the external validation resulting in better model with $\mathrm{RMSE}_{\mathrm{VE}} 9.51 \mathrm{~N}$ and $\mathrm{R}_{\mathrm{VE}}^{2}$ of 0.40 and the prediction set with RMSE of $13.2 \mathrm{~N}, \mathrm{R}_{\mathrm{P}}{ }^{2} 0.40$ with $7 \mathrm{LV}_{\mathrm{S}}$. The NIR spectroscopy showed to be a potential analytical method to determine SSC and firmness of intact low chilling 'Aurora 1' cultivar. However, it is necessary to optimize the models in other to reduce the prediction errors.
\end{abstract}

(C) 2015 Elsevier B.V. All rights reserved.

\section{Introduction}

In temperate regions peach trees (Prunus persica L.) require exposure to chilling temperatures during the winter to overcome the rest period, after which normal bud break and development can occur (Campoy et al., 2011; Viti et al., 2010). The duration of chilling length required to bud break of a given cultivar is known as the chilling requirement of that particular cultivar (Wagner Júnior et al., 2013), and it varies greatly from $1050 \mathrm{~h}$ in 'Contender' to $600 \mathrm{~h}$ in 'LaFeliciana' (Parker and Werner, 2015). On the other hand,

\footnotetext{
* Corresponding author. Fax: +55 1632092668.

E-mail addresses: gustavo@fcav.unesp.br, teixeiragha@yahoo.com.br (G.H.d.A. Teixeira).
}

in subtropical and tropical regions the cultivation of peach trees is possible due to agronomic innovations and the development of low chilling cultivars, which require low exposure to chilling temperatures (100 to $200 \mathrm{~h}$ ).

In Florida, USA, Ferguson et al. (2015) reported various low chilling cultivars, such as, 'Flordaprince' and 'Tropicalbeauty' with $150 \mathrm{~h}$ estimated chilling units, and 'UFSun' with $100 \mathrm{~h}$. In subtropical regions of Brazil the cultivation of peach trees is carried out also with low chilling cultivars originated from local breading programs, for example the cultivar Aurora 1 (Ojima et al., 1989). The cultivar Aurora- 1 requires less than the $100 \mathrm{~h}$ of chilling period to bud break. Its fruit has oblong shape, weights around $100 \mathrm{~g}$, and presents a red blush colour (80\% color over yellow background), and the fruit has also excellent sensory quality, with 
firm flesh, yellow pulp, and high soluble solids content (SSC), approximately 14\% (Cunha Junior et al., 2007; Donadio, 2010).

Peach quality is greatly affected by the soluble solids content and it influences the acceptance of peach fruit by the consumers. Crisosto et al. (2013) reported 70\% consumer acceptance when 'Elegant Lady' peach had $13 \%$ of SSC, on the other hand, when SSC were less than $11 \%$ there was little receptivity by consumers. Consumers also evaluate the firmness as an important quality parameter. Kader (2002) reported that fruit with a firmness of 27-36 Newton (N) can be considered "ready-to-buy" and with 9 to $13 \mathrm{~N}$ considered ripe "ready-to-eat".

The determination of SSC and firmness are based on simple analytical methods (AOAC, 1997), but both determinations are destructive, time consuming, and are not adequate to monitor peach quality in modern grading lines. One alternative method is the use of near infrared (NIR) spectroscopy as this method has been used to determine internal quality attributes of various fruit (Nicolaï et al., 2007; Mariani et al., 2014; Viegas et al., 2016). Regarding peach fruit, Golic and Walsh (2006) developed a combined model for several peach and nectarine cultivars to determine SSC. Golding et al. (2006) used a portable NIR to predict SSC in peach fruit at different maturity stages. The development of models to predict SSC in peach fruit is the most common use of NIR spectroscopy (Ying et al., 2005; Shao et al., 2011), but firmness (Fu et al., 2008; Lafuente et al., 2015) and flesh colour (Slaughter et al., 2013) were also studied. Although various studies can be found regarding the use of NIR spectroscopy evaluating peach fruit quality, the developed models were built based on cultivars with high chilling requirements and with fruit produced in temperate regions. These models cannot be used in subtropical and/or tropical regions to monitor peach quality, as the cultivars and environment are very different, thus, it is necessary the development of models for peach fruit produced in these conditions.

Therefore, the objectives of this study was to develop partial least square (PLS) models using NIR spectroscopy for the determination of SSC and firmness in intact low chilling 'Aurora-1' peach fruit, and verify the influence of maturity stage and harvest season on the models to be developed (robustness).

\section{Materials and methods}

\subsection{Fruit material}

Peach fruit were harvest in commercial orchards of Val Frutas,

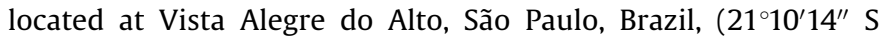
latitude, $48^{\circ} 37^{\prime} 45^{\prime \prime} \mathrm{W}$ longitude, and $700 \mathrm{~m}$ altitude). A total of 539 intact peach fruit of the low chilling cultivar Aurora 1 were collected in 2013 and 2014. The fruit were harvest in three maturity stages, as such: physiological mature (100-115 hue angle), ripe (106-80 hue angle), and over-ripe (hue angle lower than 80 ) based on the recommendations of Cunha Junior et al. (2007). The fruit were also harvested at the beginning, in the middle and at the end of the crop season in 2013 to build the calibration and validation models, and at the beginning of the harvest season in 2014, to build the prediction model (Table 1 ).

\subsection{FT-NIR spectra acquisition}

The spectra were collected using a FT-IR Spectrum $100 \mathrm{~N}$ (PerkinElmer, Shelton, CT, USA). The spectrometer was equipped with Near Infrared Reflectance Accessory (NIRA), an integrating sphere and InGaAs detector. The light source was a halogen lamp. Diffuse reflectance spectra were obtained over the range of $4000-0,000 \mathrm{~cm}^{-1}(1000-2500 \mathrm{~nm})$ at a spectral resolution of $8 \mathrm{~cm}^{-1}$ with 64 scans per spectra. The $\log 1 / \mathrm{R}$ spectra were referred as absorbance spectra for convenience.

Fruit were set onto the NIRA and two spectra were collected on the equator of both sides of each fruit (blush and background color), equidistant from proximal and distal ends (Subedi et al., 2007). Each spectrum was used as individual sample in the models. After spectra acquisition, fruit were subjected to analytical determinations, considering the same areas of spectral analysis.

\subsection{Reference analysis}

\subsubsection{Colour}

$\mathrm{L}^{*}, \mathrm{a}^{*}$ and $\mathrm{b}^{*}$ colour coordinates were determined using $\mathrm{a}$ Minolta colorimeter CR 400 (Minolta, Osaka, Japan). L measures luminosity, while $\mathrm{a}^{*}$ and $\mathrm{b}^{*}$ values index the red-green and yellowblue space, respectively. Determinations were taken on the two sides of each fruit (blush and background colour) at the same areas where the NIR spectra were acquired. It was also calculated the hue angle, arc tangent of $\left(b^{*} / a^{*}\right)$, and chromaticity, $\left(C^{*}\right)\left(\left[\left(a^{*}\right) \times 2+\right.\right.$ $\left.\left.\left(b^{*}\right) \times 2\right] \times 0.5\right)$ according to the method described by McGuire (1992). Fruit were reclassified according to the maturation stages by the hue angle according to Cunha Junior et al. (2007), physiological mature $\left(100-115^{\circ}\right)$, ripe $\left(106-80^{\circ}\right)$ and over-ripe (hue angle of $<80^{\circ}$ ).

\subsubsection{Firmness}

Firmness was determined using a penetrometer Bishop FT 327, Italy, using an $8 \mathrm{~mm}$ tip. The results were expressed in Newton $(\mathrm{N})$, on the same two positions where the NIR spectra were acquired. The laboratory error for this determination was $4.02 \mathrm{~N}$.

\subsubsection{Soluble solids content (SSC)}

The fruit parts where the NIR spectra were collected were also used to analysed the soluble solids content according to the reference method 920.151 reported by AOAC (1997). It was used a refractometer (Alpha, Atago Co., Ltd, Japan). The measurements were carried out in duplicate and the results were expressed in percentage (\%). The laboratory error for this determination was $0.4 \%$.

\subsection{Chemometrics}

The Unscrambler version 10.3 (Camo, Oslo, Norway) was used for data analysis. Spectra were pre-processed using Standard Normal Variate, (SNV), Multiplicative Scatter Correction (MSC), $\mathrm{SNV}+$ De-Trend, second polynomial order of the first $\left(\mathrm{d}^{1} \mathrm{~A}\right)$ of Savitzky-Golay with smoothing window five points $(2+2)$.

Table 1

Descriptive statistics of the calibration and validation set (2013), and the prediction set (2014) classified with the classic Kernnard-Stone selection algorithm.

\begin{tabular}{|c|c|c|c|c|c|c|c|c|c|}
\hline \multirow[b]{2}{*}{ Group } & \multirow[b]{2}{*}{$\mathrm{N}^{\mathrm{a}}$} & \multicolumn{4}{|c|}{ Soluble Solids Content (SSC-\%) } & \multicolumn{4}{|c|}{ Firmness (Newton - N) } \\
\hline & & Mean & $\mathrm{SD}^{\mathrm{b}}$ & Maximum & Minimum & Mean & SD & Maximum & Minimum \\
\hline Calibration & 340 & 11.2 & 1.66 & 17.6 & 6.6 & 44.1 & 14.7 & 111.7 & 4.9 \\
\hline Validation & 90 & 11.4 & 1.68 & 16.0 & 6.3 & 42.1 & 12.2 & 78.4 & 10.8 \\
\hline Prediction & 109 & 12.7 & 1.38 & 17.0 & 9.2 & 53.9 & 13.9 & 84.3 & 15.7 \\
\hline
\end{tabular}

a $\mathrm{N}=$ number,

b $\mathrm{SD}=$ standard deviation. 
Calibration and validation models were developed using the data set from 2013 (430 fruit). The samples were divided into two groups, the calibration set $(n=340)$ and validation set $(n=90)$ using the classic selection algorithm of Kernnard-Stone (Kennard and Stone, 1969). The prediction was carried out using the samples from $2014(n=109)$ which were not included in the calibration set (Table 1). Principal component analysis (PCA) was considered to study the influence of the external variables (maturity stages, harvest seasons, and year) to build partial least squares regression (PLSR) models. Model performance was described by the statistical terms of coefficient of determination of calibration $\left(R_{\mathrm{C}}{ }^{2}\right)$, the root mean square error of calibration (RMSE $E_{C}$ ), coefficient of determination of external validation $\left(R_{\mathrm{VE}}^{2}\right)$, the root mean square error of external validation $\left(\mathrm{RMSE}_{\mathrm{VE}}\right)$ and prediction, coefficient of determination of prediction $\left(R_{\mathrm{P}}{ }^{2}\right)$, root mean square error of prediction $\left(\mathrm{RMSE}_{\mathrm{P}}\right)$, bias corrected $\mathrm{RMSE}_{\mathrm{P}}$, and ratio of the standard

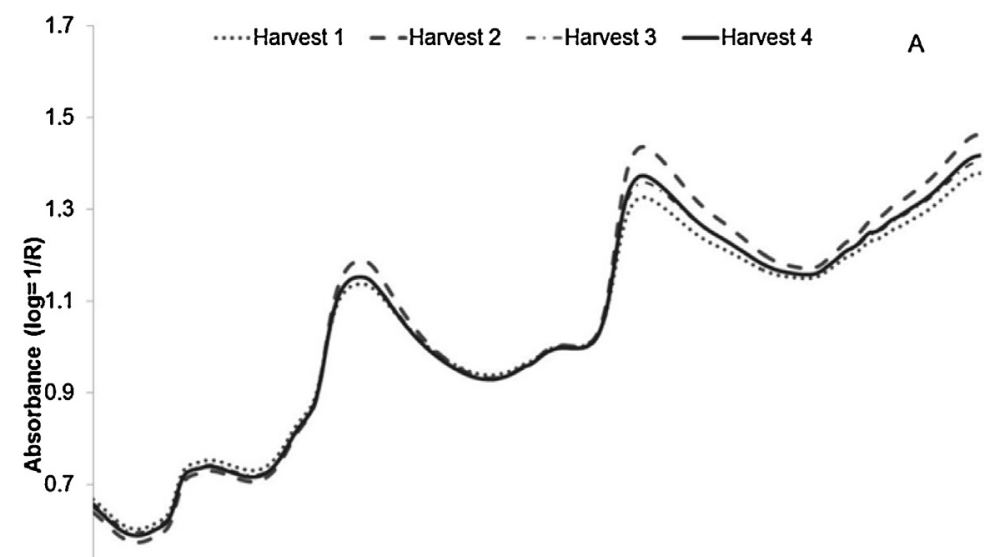

0.5
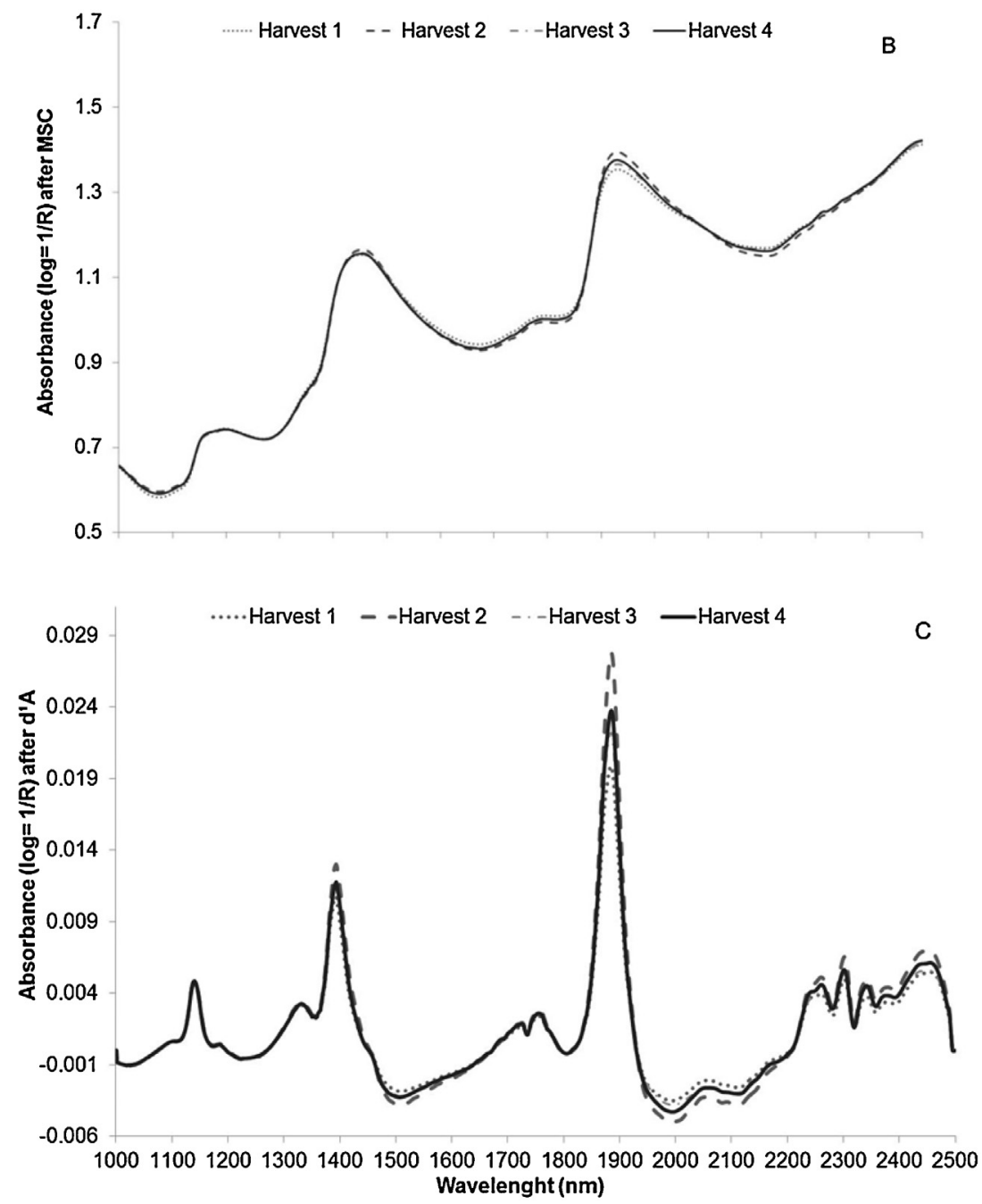

Fig. 1. NIR spectra, raw spectra (A); multiplicative scatter correction (MSC) (B), first derivative of Savitsky-Golay (d $\left.{ }^{1} A\right)(C)$. 
deviation of SSC and firmness to bias corrected $\operatorname{RMSE}_{\mathrm{P}}\left(\mathrm{SDR}_{\mathrm{p}}\right)$, (Golic and Walsh, 2006; Nicolaï et al., 2007).

\section{Results and discussion}

\subsection{NIR spectra}

The mean raw NIR spectra of each harvest can be seen in Fig. $1 \mathrm{~A}$. The spectra showed two important regions and spectra were dominated by the presence of water. As intact peach fruit have 8595\% moisture the predominant peaks were related to $\mathrm{OH}$ stretch observed between $1400-1500 \mathrm{~nm}$ and at $1900-2000 \mathrm{~nm}$, related to the $\mathrm{OH}$ asymmetric stretch and bending combinations (Osborne et al., 1993). Two other small peaks were observed between 1100$1200 \mathrm{~nm}$ and at $1800 \mathrm{~nm}$ being related to the presence of sugar, which are the second and third $\mathrm{CH}$ overtone, respectively (Osborne
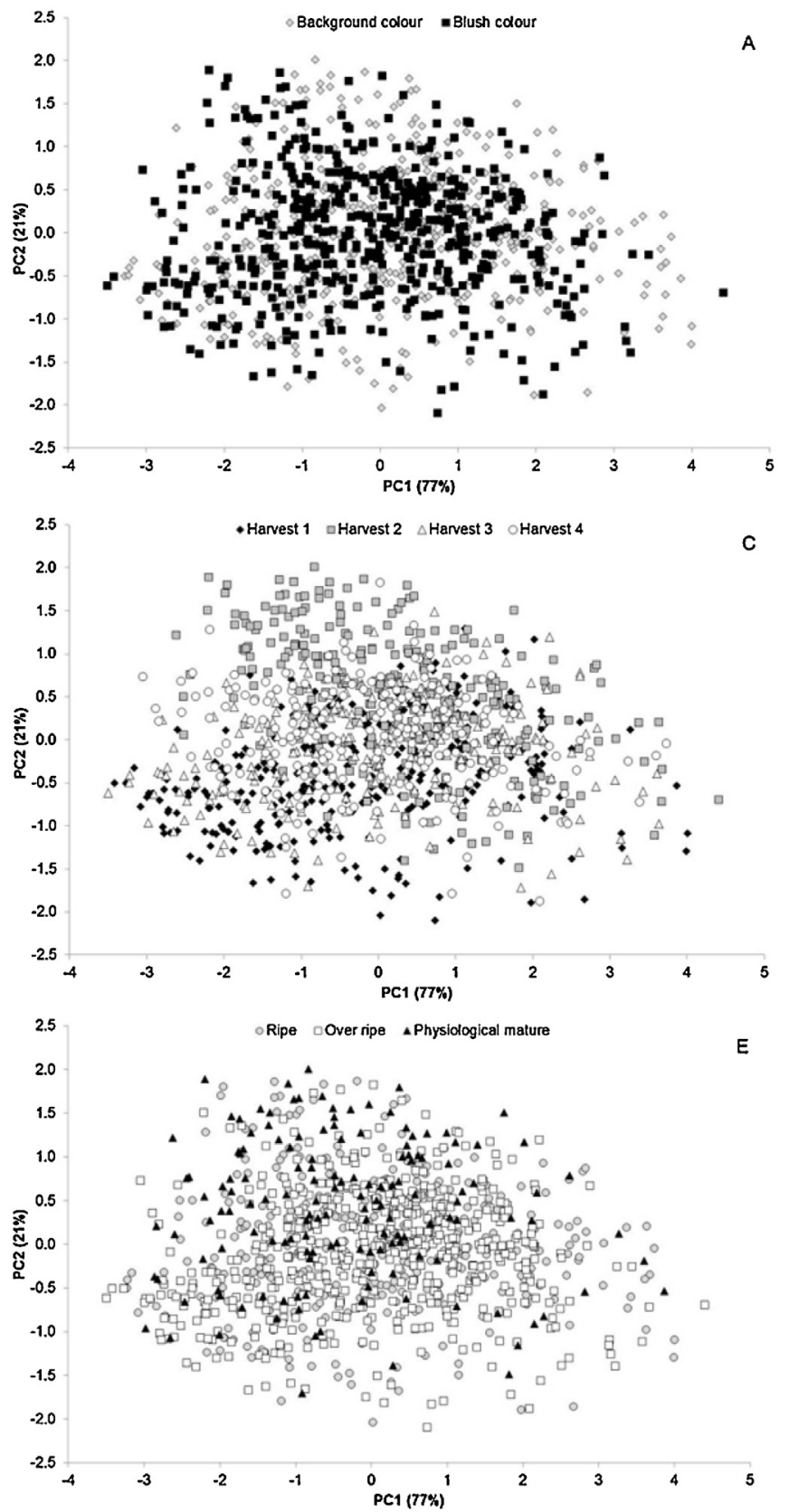

et al., 1993; Louw and Theron, 2010). Light scattering was observed and it was mainly due to the presence of velvet skin in 'Aurora 1' peach fruit. In other to reduce the influence of light scattering and the base line drift various pre-processing were applied to the spectra, and MSC and first derivative of Savitsky-Golay with five smoothing point $\left(\mathrm{d}^{1} \mathrm{~A}\right)$ were considered the best results (Fig. $1 \mathrm{~B}$ and $\mathrm{C}$ ).

\subsection{Principal component analysis (PCA)}

PCA was used to observe the variations due to spectra acquisition (blush and background color), harvest season and maturity stage (Fig. 2). For PCA it was used a total of 539 fruit, which corresponded to 1078 spectra with no pre-processing.

As 'Aurora 1' peach fruit has the skin with two colors (blush and background color) and this differences could influence the
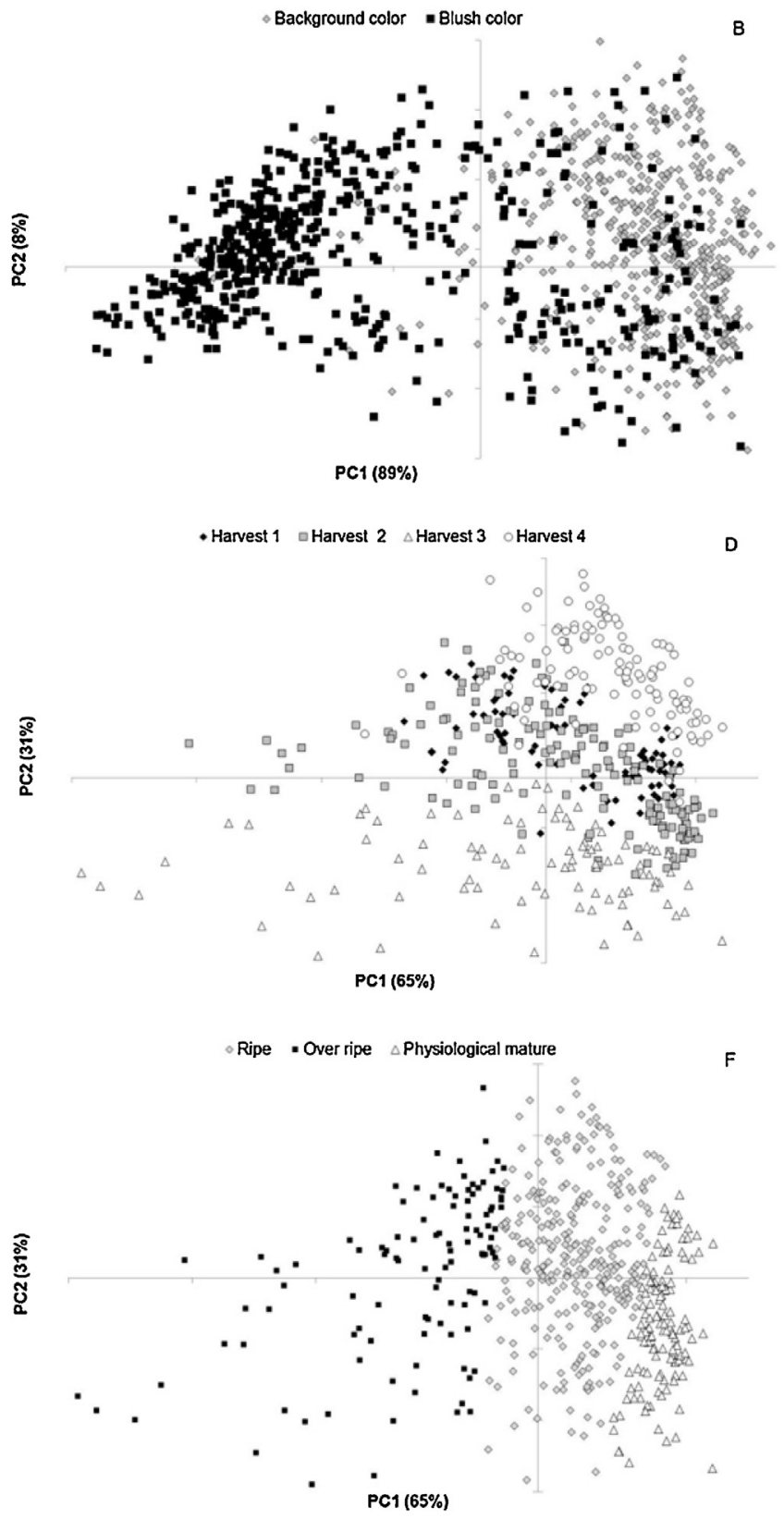

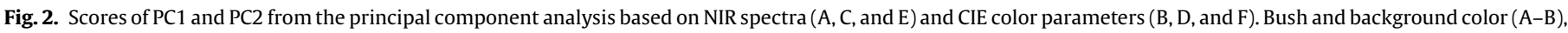
harvest seasons $(C-D)$, and maturity stages $(E-F)$. 
Table 2

Performance of PLS models developed using NIR spectra of intact 'Aurora 1' peach fruit for soluble solids determination (\%).

\begin{tabular}{|c|c|c|c|c|c|c|c|c|}
\hline & \multicolumn{2}{|c|}{ Calibration } & \multicolumn{2}{|c|}{ External validation } & \multicolumn{4}{|c|}{ Prediction } \\
\hline & $\mathrm{RMSE}_{\mathrm{C}}$ & $R_{\mathrm{C}}^{2}$ & RMSE $_{\mathrm{VE}}$ & $R_{\mathrm{VE}}^{2}$ & RMSE $_{P}$ & SEP & $R_{\mathrm{P}}{ }^{2}$ & ${ }^{a} \mathrm{RPD}$ \\
\hline PLS (11), original & 1.07 & 0.59 & 1.15 & 0.53 & 1.05 & 1.02 & 0.45 & 1.35 \\
\hline PLS (11), MSC & 1.01 & 0.63 & 1.08 & 0.59 & 1.04 & 1.02 & 0.45 & 1.36 \\
\hline PLS (11), SNV & 1.02 & 0.63 & 1.09 & 0.58 & 1.04 & 1.03 & 0.45 & 1.36 \\
\hline PLS (11) SNV + De trend & 1.01 & 0.63 & 1.08 & 0.59 & 1.04 & 1.03 & 0.45 & 1.36 \\
\hline PLS (11), $d^{1} A$ & 0.89 & 0.72 & 1.35 & 0.36 & 1.29 & 1.11 & 0.40 & 1.10 \\
\hline
\end{tabular}

${ }^{a} \mathrm{RPD}=$ standard deviation ratio $\left(\mathrm{SD} / \mathrm{RMSE}_{\mathrm{P}}\right)$.

development of PLS models, the NIR spectra were collected in both color regions. However, it was not observed any cluster formation between the samples (Fig. 2A) with PC1 and PC2 representing 98\% of the data explained variance. This result can be an advantage, because regardless of the property to be analysed, there is no need to place the fruit in a specific position for NIR spectra acquisition. On the other hand, when PCA was carried out using the CIE color parameters it was possible to separate the fruit based on blush and background color (Fig. 2B).

PCA was also carried out to verify the differences between harvest seasons with fruit harvested at the beginning (harvest 1 ), in the middle (harvest 2) and at the end of the harvest season (harvest 3 ) in 2013, and at the beginning of the harvest season in 2014 (harvest 4), Fig. 2C. Again there was no cluster formation among harvest seasons with the samples presenting the same distribution with PC1 and PC2 also representing 98\% of the variance. Using the color parameters it was also not possible to separate fruit base on the different harvests (Fig. 2D).

Similarly, to the other variations, the differences in maturity stages (physiologically mature, ripe, and over-ripe) did not form any cluster with samples overlapping regardless the maturity stage (Fig. 2E). On the other hand, with the CIE color parameters is was possible to separate the fruit based on the different maturity stages (Fig. 2F), showing that the fruit were physiologically different, but the NIR could not detect such differences. Although the PCA did not showed any difference between the sample variations the incorporation of these variability are of paramount importance. Tiwari et al. (2013) reported superior performance when models were developed with the incorporation of different cultivars and harvest seasons. Nicolaï et al. (2007) also highlighted the necessity to incorporate into the models as much information as possible to obtain a robust prediction model.

Likewise, there was no cluster formation among the variations of the samples when the NIR spectra were pre-processed (data not shown).

\subsection{PLS prediction models: soluble solids content (SSC)}

The descriptive statistics of the sample set for SSC can be seen in Table 1. The calibration statistics of the PLS models obtained with the raw and pre-processed NIR spectra (MSC, SNV, SNV+ De-trend and $d^{1} A$ ) are shown in Table 2 . The best performance of the SSC calibration model was developed with NIR spectra pre-processed with MSC and SNV (Table 2), both were used to reduce the influence of light scattering. These models had the lowest values of RMSE $_{\mathrm{C}}(1.01-1.02 \%)$ and higher $R_{\mathrm{c}}{ }^{2}(0.63)$. For the validation set using Kennard-Stone algorithm, the best results were also obtained with MSC and SNV with a RMSE $E_{\mathrm{VE}}$ of 1.08 and $1.09 \%$, respectively, and $a R_{V E}^{2}$ of 0.59 and 0.58 . The robustness of the developed model was tested using an external prediction set composed by fruit from a difference year (2014). Again, the MSC and SNV pre-processing resulted in better prediction models with both showing a SEP of $1.02 \%, \mathrm{R}_{\mathrm{P}}{ }^{2}$ of 0.45 and RPD of 1.36 . The comparison between the predicted SSC values and the values obtained with the reference method are shown in Fig. 3.

Although the determination coefficients $\left(R^{2}\right)$ of the validation and prediction sets were below $0.70\left(R_{\mathrm{VE}}{ }^{2}=0.59\right.$ and $R_{\mathrm{P}}{ }^{2}=0.45$, respectively), the $\mathrm{RMSE}_{\mathrm{C}}$ and $\mathrm{RMSE}_{\mathrm{VE}}$ were very low, ranging from 0.89 to $1.35 \%$, respectively. These results are in agreement to Nicolaï et al. (2007), who reported values of 1.0 to $1.5 \%$ as being

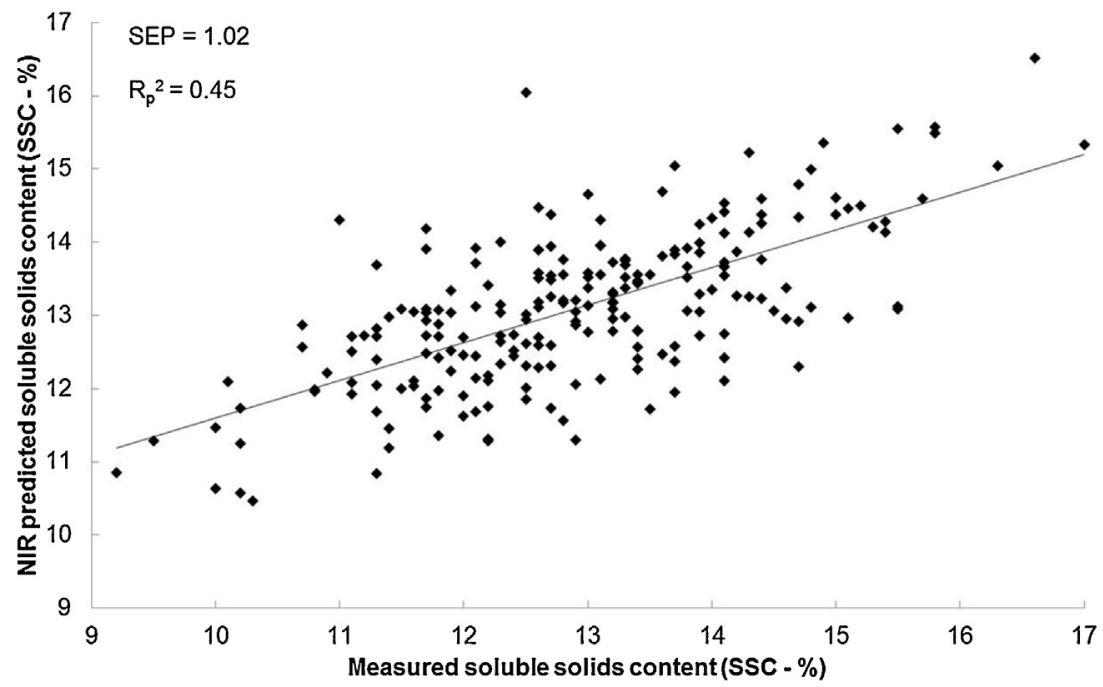

Fig. 3. Reference (measured) and predicted values of soluble solids content (SSC-\%) in intact peach fruit 'Aurora 1'. PLS regression MSC correction. 
Table 3

Performance of PLS models developed using NIR spectra of intact 'Aurora 1' peach fruit for fruit firmness (N).

\begin{tabular}{|c|c|c|c|c|c|c|c|c|}
\hline \multirow[t]{2}{*}{ Models } & \multicolumn{2}{|c|}{ Calibration } & \multicolumn{2}{|c|}{ External validation } & \multicolumn{4}{|c|}{ Prediction } \\
\hline & RMSE $_{\mathrm{C}}$ & $R_{\mathrm{C}}^{2}$ & RMSE $_{\mathrm{VE}}$ & $R_{\mathrm{VE}}^{2}$ & RMSE $_{P}$ & SEP & $R_{\mathrm{P}}{ }^{2}$ & ${ }^{\mathrm{a}} \mathrm{RPD}$ \\
\hline PLS (7), original & 11.0 & 0.54 & 9.8 & 0.35 & 13.7 & 11.2 & 0.35 & 1.01 \\
\hline PLS (7), MSC & 11.1 & 0.53 & 9.9 & 0.34 & 13.3 & 11.4 & 0.34 & 1.04 \\
\hline PLS (7), SNV & 11.0 & 0.54 & 10.0 & 0.33 & 13.8 & 11.5 & 0.32 & 1.01 \\
\hline PLS (7) SNV + De trend & 11.2 & 0.52 & 9.8 & 0.35 & 13.0 & 11.5 & 0.32 & 1.07 \\
\hline $\operatorname{PLS}(7), d^{1} A$ & 9.3 & 0.67 & 9.5 & 0.40 & 13.2 & 10.8 & 0.40 & 1.05 \\
\hline
\end{tabular}

a $\mathrm{RPD}=$ standard deviation ratio $\left(\mathrm{SD} / \mathrm{RMSE}_{\mathrm{P}}\right)$.

consistent with studies that used external validation groups, with fruit coming from different orchards and periods of the year.

NIR spectroscopy has been used for the development of SSC prediction models in other peach fruit cultivars. Shao et al. (2011) reported values RMSE $\mathrm{P}$ of $0.42 \%$ and $R^{2}$ of 0.95 in 'Milu' and 'Hongxianju' peach cultivars. Ying et al. (2005) also investigated the SSC determination in 'Honey' and 'Sweet' peach cultivars, and reported SEP values of $0.53 \%$ and the $R^{2}$ of 0.92 . Portable NIR spectrometer was also use to evaluate SSC in peach fruit in different maturity stages by Golding et al. (2006), with a reported $\mathrm{RMSE}_{\mathrm{CV}}$ of $0.36 \%$ and a $R^{2}$ of 0.91 . All these studies showed better determination coefficients, but the models were developed with cultivars grown in temperate regions, with higher chilling requirements, and in different countries, therefore these models cannot be used and/or transferred to subtropical and tropical peach growing regions. According to Golic and Walsh (2006) many variables, e.g. temperature, geographic region, picking time, cultivar, data pre-treatment and model algorithm, can affect the performance of a predictive model. It is therefore expected that the model prediction statistics for a truly independent population will be poorer than the calibration statistics $\left(\operatorname{RMSE}_{\mathrm{P}}>\mathrm{RMSE}_{\mathrm{CV}}\right)$.

The RPD values were considered very low (Table 2 ), in the prediction group it was possible to get a RPD of 1.36 , which can allows discrimination of fruit with low from high SSC. According to Nicolaï et al. (2007), a model can discriminate variables with low from high levels when the RPD values are between 1.5 and 2, a coarse quantitative prediction is possible when the RPD values are between 2 and 2.5, and a good to excellent prediction accuracy is possible when the values are between 2.5 and 3 . Therefore, the bigger the RPD value the better the model probability to predict the chemical composition of external samples out of the calibration set (Smyth et al., 2008).

\subsection{PLS prediction models: firmness}

The descriptive statistics of the sample set for firmness can be seen in Table 1. The calibration statistics of the PLS models obtained with the raw and pre-processed NIR spectra (MSC, SNV, $\mathrm{SNV}+$ De-trend, and $\mathrm{d}^{1} \mathrm{~A}$ ) are shown in Table 3 .

Similar to Barbosa et al. (2010), it was observed a lower performance for the PLS firmness models with lower $R^{2}$ values and higher errors than for SSC. The best calibration, validation and prediction PLS firmness models performances were developed with NIR spectra pre-processed with the first derivative of Savitsky-Golay $\left(\mathrm{d}^{1} \mathrm{~A}\right)$, Table 3 . The calibration model had the lowest $\operatorname{RMSE}_{\mathrm{C}}$ value $(9.3 \mathrm{~N})$ and highest $R_{\mathrm{c}}^{2}(0.67)$. The external validation set also generated the lowest $\operatorname{RMSE}_{\mathrm{VE}}(9.5 \mathrm{~N})$ and $R_{\mathrm{VE}}{ }^{2}$ (0.40). Similarly, to SSC, the SEP values increased when the prediction was carried out using the fruit from the 2014 harvest. The observed SEP was of $10.8 \mathrm{~N}$ and the $R_{\mathrm{P}}{ }^{2}$ of 0.40 , with a RDP of 1.05 (Table 3). One possible explanation of the performance obtained with the prediction set was a severe drought in 2014 at the peach production area (CPTEC, 2015), which might have affected the fruit quality. However, the inclusion of all possible sources of variation is imperative to increase the robustness of the models (Nicolaï et al., 2007; Sánchez et al., 2011). The comparison between the predicted firmness values and the reference values are shown in Fig. 4.

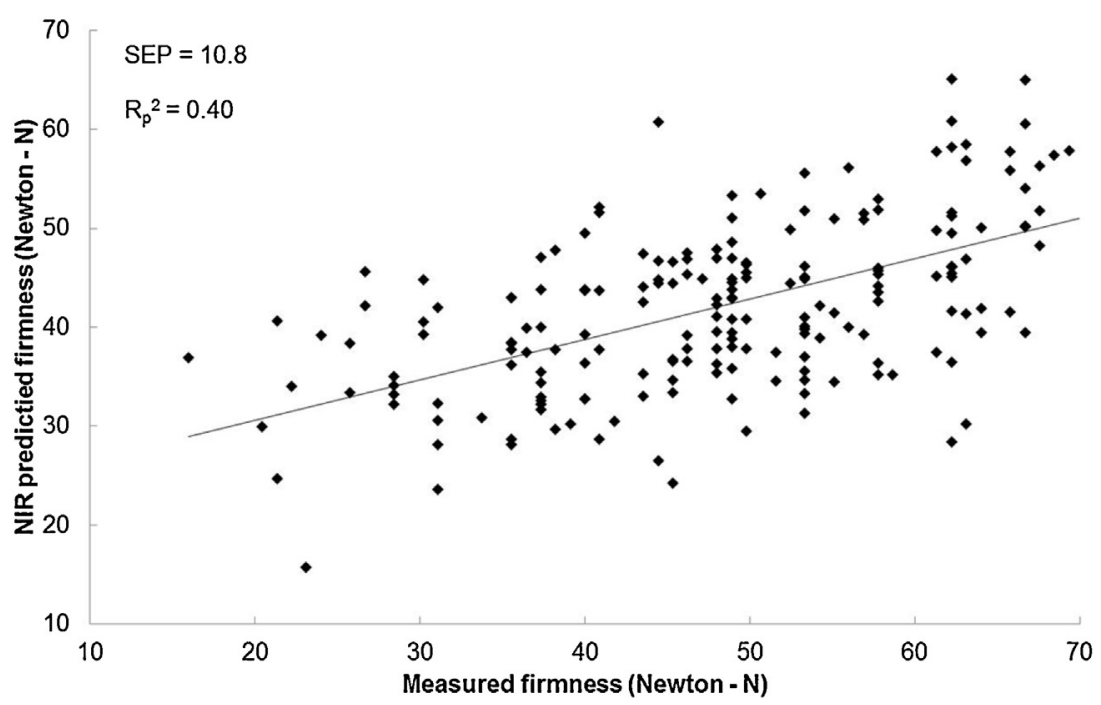

Fig. 4. Reference (measured) and predicted values of firmness $(\mathrm{N})$ in intact peach fruit 'Aurora 1 '. PLS regression with first derivative of Savitsky-Golay ( $\left.{ }^{1} \mathrm{~A}\right)$. 
The NIR spectroscopy has been also used to determine firmness in peach fruit. Using the cultivar 'Calrico', Lafuente et al. (2015) developed PLS models for predicting firmness with a RMSE $\mathrm{CV}_{\mathrm{CV}}$ of 0.9 MT (Magness-Taylor test), $R_{\mathrm{CV}}{ }^{2}$ of 0.77 , and a RPD of 1.97. Fu et al. (2008) determined firmness of different peach cultivars reported a RMSE $_{\mathrm{CV}}$ of $6.3 \mathrm{~N}, \mathrm{SEP}$ of $5.4 \mathrm{~N}$ and a $R^{2}$ of 0.87. Betemps et al. (2014) using a NIR-Case of Sacmi ${ }^{\circledR}$ reported SEP values ranging from 12.1 to $32.7 \mathrm{~N}$ and $R^{2}$ from 0.16 to 0.63 for the cultivars 'Chimarrita', 'Maciel', 'Eldorado' and 'Jubileu', all with high chilling requirements peach cultivars. This variation shows that single cultivar models are possibly more accurate and reliable than a multi cultivar model (Golic and Walsh, 2006). However, Louw and Theron (2010) reported that multi cultivar models have an equal or better precision than single ones. The inclusion of different cultivars generates more robust models. The RPD values for the firmness models (Table 3 ) were lower than for SSC (Table 2). The prediction set model showed a RPD of just 1.05, which according to Nicolaï et al. (2007) does not even allow quantitative predictions from low to high levels..

Although robust calibration models are obtained using different cultivars and different production years than analysing individual cultivar (Tiwari et al., 2013), our results are the first attempt to use NIR spectroscopy to predict SSC and firmness in low chilling peach fruit cultivar which incorporated variability regarding harvest season, maturity stages to increase robustness.

\section{Conclusions}

PCA could not group the fruit based on blush and background skin color, maturity stages, and harvest season when NIR spectra was used, but when CIE color parameters were used it was possible to separate the fruit based on the blush and background skin color, and in function to the maturity stages.

The best SSC prediction model for an independent group was obtained with NIR spectra pre-processed with MSC (SEP $=1.02 \%$, $R_{\mathrm{P}}{ }^{2}=0.45$, and $\mathrm{RPD}=1.36$ ), and for firmness the best model was developed applying the first derivative of Savitsky-Golay (SEP = $10.8 \mathrm{~N}, R_{\mathrm{P}}{ }^{2}=0.40$, and $\mathrm{RDP}=1.05$ ).

The NIR spectroscopy showed to be a potential analytical method to determine SSC and firmness of intact low chilling 'Aurora 1' cultivar. However, it is necessary to optimize the models in other to reduce the prediction errors.

\section{Acknowledgments}

The authors would like to thank CAPES for the providing the Master scholarship of the first author, and Fundação de Amparo à Pesquisa do Estado de São Paulo (FAPESP) for funding this research: process number 2008/51408-1.

\section{References}

AOAC, 1997. Official Methods of Analysis of the Association of Official Analytical Chemists, sixteenth ed. Patricia Cuniff, Arlington.

Barbosa, W., Neto Dall'Orto, J.E.B.F.A.C., Tecchio, M.A., 2010. Pêssego e nectarina. In: Donadio, L.C. (Ed.), História da fruticultura Paulista. ed. Sociedade Brasileira de Fruticultura. Jaboticabal, pp. 285-302.

Betemps, D.L., Fachinello, J.C., Galarça, S.P., Machado, N.P., Remorini, D., Massai, R. Agati, G., 2014. Espectroscopia do vísivel e infra-vermelho próximo para estimar sólidos solúveis e firmeza de polpa em função da época de colheita em pêssegos. Ciên Agrárias 35, 1257-1266.

Campoy, J.A., Ruiz, D., Egea, J., Rees, D.J.G., Celton, J.M., Martínez- Gómez, P., 2011. Inheritance of flowering time in apricot (Prunus armeniaca L.) and analysis of linked quantitative trait loci (QTLs) using simple sequence repeat (SSR) markers. Plant Mol. Biol. Rep. 29, 404-410.

CPTEC, 2015. CPTEC-Centro de Previsão do Tempo e Estudos Climáticos. Available in http://tempo.cptec.inpe.br/ (accesssed 20.03.15.).
Crisosto, C.H., Crisosto, G., Bowerman, E., 2013. Searching for consumer satisfaction: new trends in the California peach industry. 1st Mediterranean Peach Symposium, Italy .

Cunha Junior, L.C., Durigan, M.F.B., Mattiuz, B.H., Martins, R.N., Durigan, J.F. 2007. Caracterização da curva de maturação de Pêssegos 'Aurora-1', na região de Jaboticabal- SP. Rev. Bras. Frut. 29, 661-665.

Ferguson, J., Andersen, P., Chaparro, J., Williamson, J., 2015. Florida subtropical peaches: general concepts and cultivars recommended for grower trials. Document HS1125, January 2008. Available in: http://edis.ifas.ufl.edu (accesssed 28.04.15.).

Fu, X.-Ping, Ying, Y.-Bin, Zhou, Y., Xie, L.-Juan, Xu, H.-Rong, 2008. Application of NIR spectroscopy for firmness evaluation of peaches. J. Zhejiang Univ. Sci. 9, 552557.

Golding, J.B., Satyan, S., Liebenberg, C., Walsh, K., McClasson, W.B., 2006. Application of portable NIR for measuring soluble solids concentrations in peaches. ISHS Acta Hort. 713.

Golic, M., Walsh, K.B., 2006. Robustness of calibration models based on near infrared spectroscopy for the in-line gradins of stone fruit for total soluble solids content. Anal. Chim. Acta. 555, 286-291.

Kader, A.A., 2002. Postharvest Technology of Horticultural Crops, third ed. California Agriculture and Natural Resources, Davis pp. 350.

Kennard, R.W., Stone, L.A., 1969. Computer aided design of experiments. Technometrics 11, 137-148.

Lafuente, V., Herrera, L.J., Pérez, M.M., Val, J., Negueruela, I., 2015. Firmness prediction in Prunus persica 'Calrico' peaches by Visible/short wave near infrared spectroscopy and acoustic measurements using optimised linear and non-linear chemometric models. J. Sci. Food Agric. 95, 2033-2040.

Louw, E.D., Theron, K.I., 2010. Robust prediction models for quality parameters in Japanese plums (Prunus salicina L.) using NIR spectroscopy. Postharvest Biol. Technol. 58, 176-184.

Mariani, N.C.T., Costa, R.C., Lima, K.M.G., Nardini,V, Cunha Júnior, L.C., Teixeira, G.H. A., 2014. Predicting soluble solid content in intact jaboticaba [Myrciaria jaboticaba (Vell.) O. Berg] fruit using near-infrared spectroscopy and chemometrics. Food Chem. 159, 458-462.

McGuire, R.G., 1992. Reporting of objective color measurements. HortScience 27, 254-255.

Nicolaï, B.M., Beullens, K., Bobelyn, E., Peirs, A., Saeys, W., Theron, K.I., Lammertyn, J., 2007. Nondestructive measurements of fruit and vegetable quality by means of NIR spectroscopy: a review. Postharvest Biol. Technol. 46, 99-118.

Ojima, M., Dall'Orto, F.A.C., Barbosa, W., Martins, F.P., dos Santos, R.R., Rigitano. 1989. O. 'Aurora-1' e 'Aurora-2': novas cultivares de pêssego doce de polpa amarela. In: Congresso Brasileiro de Fruticultura, 10, Fortaleza, Anais. Fortaleza: SBF, $422-425$.

Osborne, B.G., Fearn, T., Hindle, P.H., 1993. Practical NIR. spectroscopy with applications in food and beverage analysis, second ed. Longman Group, Burnt Mill, Harlow, Essex.

Parker, M., Werner, D., 2015. Horticultural chilling requirements of selected peach varieties. Horticulture Information Leaflet, April 2015. Available in: http:// content.ces.ncsu.edu/chilling-requirements-of-selected-peach-varieties (accesssed 28.04.15.).

Sánchez, M.T., Haba, M.J., Guerrero, J.E., Varo, A.G., 2011. Testing of a local approach for the prediction of quality parameters in intact nectarines using a portable NIRS instrument. Postharvest Biol. Technol. 60, 130-135.

Shao, Y., Bao, Y., He, Y., 2011. Visible/Near-Infrared Spectra for Linear and Nonlinear Calibrations: A Case to Predict Soluble Solids Contents and pH Value in Peach. Food Bioprocess Technol. 4, 1376-1383.

Slaughter, D.C., Crisosto, C.H., Tiwari, G., 2013. Nondestructive determination of flesh color in clingstone peaches. J. Food Eng. 116, 920-925.

Smyth, H.E., Cozzolino, D., Cynkar, W.U., Dambergs, R.G., Sefton, M., Gishen, M., 2008. Near infrared spectroscopy as a rapid tool to measure volatile aroma compounds in Riesling wine: possibilities and limits. Anal. Bioanal. Chem. 308, 1911-1916.

Subedi, P.P., Walsh, K.B., Owens, G., 2007. Prediction of mango eating quality at harvest using short-wave near infrared spectrometry. Postharvest Biol. Technol. 43, 326-334.

Tiwari, G., Slaughter, D.C., Cantwell, M., 2013. Nondestructive maturity determination in green tomatoes using a handheld visible and near instrument. Postharvest Biol. Technol. 86, 221-229.

Viegas, T.R., Mata, A.L.M.L., Duarte, M.M.L., Lima, K.M.G., 2016. Determination of quality attributes in wax jambu fruit using NIRS and PLS. Food Chem 190, 1-4.

Viti, R., Andreini, L., Ruiz, D., Egea, J., Bartokini, S., Iacona, C., Campoy, J.A., 2010. Effect of climatic conditions on the overcoming of dormancy in apricot flower buds in two Mediterranean areas: Murcia (Spain) and Tuscany (Italy). Sci. Hort. 124, 217-224.

Wagner Júnior, A., Bruckner, C.H., Silva, J.O.C., Santos, C.E.M., Pimentel, L.D., Mazaro, S.M., 2013. Chilling requirement for seed germination and phonological observations on peach cultivars. Rev. Ceres. 60, 234-241.

Ying, Y.B., Liu, Y.D., Wang, J.P., Fu, X.P., Li, Y.B., 2005. Fourier transform near-Infrared determination of total soluble solids and available acid in intact peaches. Food Process. Eng. Inst. Div. ASAE 48, 229-234. 